\title{
FROM FOREIGNERS TO CITIZENS: CONCEPTUALISING STUDENTS' ENTRY INTO DISCIPLINARY COMMUNITIES OF PRACTICE
}

\author{
G Young \& A Kotzé (Stellenbosch University)
}

\begin{abstract}
The discipline of Classics, like most other disciplines in Higher Education contexts, faces numerous challenges related to changed national and international expectations. This article argues that in order to meet these challenges the discipline needs to reflect on its activities and teaching practices in a structured and deliberate way. Such reflection can be facilitated by theoretical frameworks designed in education research. We present one such framework, the "Communities of practice" as designed by Wenger (1998) and show how the framework can be employed, at a theoretical level, to conceptualise the challenges facing the discipline as well as to enhance teaching practices in an undergraduate Greek class, through an institutionally supported project. By applying this framework educators can assist students both in preparing for their careers as well as in engaging with their studies.
\end{abstract}

\section{Introduction}

The status of Classics in higher education elicits a diverse array of opinions. These range from views that Classics are under threat as a discipline (Culham \& Edmunds 1989) or that Classics are in need of radical change in order to survive as a "viable subject" (Demos 1995:321) to more positive expositions of the discipline's state of affairs. The latter are embodied in the arguments of Galinsky, who holds that there are "various roads to classical salvation" (1991:449). By responding to Culham and Edmunds (1989), Galinsky (1991) not only shows how the discipline is continuously discovering its own strengths to meet these challenges but also argues that Classics should be looking ahead in order to keep on meeting these challenges. Yet despite his optimistic assessment, Galinsky does not deny that there are Herculean challenges facing Classics as a discipline in Higher Education contexts (1991:442). These concerns, although related, can be separated into two broad categories, namely teaching and learning concerns and contextual concerns. The former refers to questions such as those posed by Kitchell et al (1996:393). They state that questions such as "Why do so few students take Greek today?" and "Why, once we get students, is the retention rate so low?" are common concerns. These teaching and learning concerns should not be considered a recent development. Consider the following claim:

If we judge by the results obtained, we are not teaching the students to translate the New Testament, to say nothing about appreciating the Greek. We are not training future Greek scholars nor fitting men to use the Greek New Testament in their own studies.

While this probably resonates with practitioners today it is in fact a claim Pottle (1937) made over 70 years ago. The second kind of concern relates more to what 
Nixon et al (2001:229) call "new educational landscapes". In referring to "new landscapes" they are highlighting, inter alia, changes in the student body (and resulting changes in practice and curriculum - an indication of how these concerns are interrelated), changes in the conditions of academic work and changes in the structures and requirements of accountability (2001:229-231). To this du Toit (2008:424) adds what she calls, “... a global tendency towards ... direct economic viability". While these challenges certainly apply to most higher education contexts, they have a particular set of characteristics in the South African context. Where, for example, many if not most institutions world-wide also struggle with underprepared students, the challenge is exacerbated in South Africa due to extreme linguistic diversity and poor quality schooling in some areas (mostly related to socio-economic status). All this leaves South African Universities with a particular kind of challenge when it comes to guiding underprepared students to where lecturers want them to be. As an individual discipline, Classics cannot expect to be able to address all of the contextual challenges (such as increased managerial pressures). It can, however, engage the teaching and learning challenges. Although speaking in the sister context of Semitics / Near Eastern studies, du Toit's assertion (2008:425) that scholars need to adapt in order to address these challenges and to ultimately ensure the survival of the discipline, also holds true for Classics.

In order to conceptualise these challenges this article adopts Wenger's (1998) "Communities of practice" framework which in turn is based on Lave and Wenger's (1991) socio-cultural notion of situated learning. This framework describes one attempt to move beyond the exclusively individualistic approach to academic disciplines (in this case Classics) by situating teaching (and learning) in the realm of the social where not only cognitive ability but also social interaction and identity play important roles in the success achieved by students. Simply put, this framework considers a community of practice to be a group who share an interest or concern for something (in this case a specific discipline). This group learns about their shared concern and improves their practice related to this concern through interaction with each other. Their interaction is guided by shared values and beliefs that contribute to the distinctiveness of the group. The next section offers a brief but more comprehensive conceptualisation of the notion of a community of practice. The "Communities of practice" framework allows us to consider some of the challenges the discipline faces in terms of categories derived from the framework, such as membership of and participation in this particular community as well as the dynamic reproduction and evolution of the community. As will be pointed out later, the establishment of an identity as a member of this community, is of vital importance to the activities and survival of this community as well as the practice of the individual since, in this framework, learning is a function of identity (O'Donnel \& Tobbel 2007:315). ${ }^{1}$

This article has three broad goals. Firstly it aims to show how the "Communities of practice" framework can be applied to the activities of the Classics discipline especially in terms of describing the identity development trajectory of new

See Sfard and Prusak 2005 for a description of the evolution of identity as a discourse in educational research. 
students entering the discipline. This will be done by offering a description of a newly launched project involving a Greek I lecturer and an educational advisor at Stellenbosch University. While the pilot phase of the project has been concluded, there is as yet little data to report from the project. Reference will be made to some of the insights gained from the pilot phase but for the most part the focus will be on describing and justifying the elements of the project. In doing this we are highlighting the fact that we believe that engaging with the theoretical foundation of the project is just as important as the actual implementation of the project. Secondly the article seeks to stimulate thinking and conversation about the professional identity/ies that are manifest in the Classics disciplinary community of practice. This is a necessary process as the discourse of a disciplinary community is often tacit but difficult to articulate. In order for academics to guide students in a systematic way in their development of a disciplinary identity the academics need to be able to make the discourses directing their discipline explicit (Jacobs 2007). This goal is interwoven with the first goal as thinking about the development of student identity is not possible without consideration of the nature, values and beliefs of the disciplinary identity that distinguishes it from identities in other communities. In order to achieve this, ongoing dialogue with established practitioners is required. Such dialogue can contribute to moving the discussion about teaching in the discipline from epistemology to ontology (Dall'Alba \& Barnacle 2007). Finally the article seeks to encourage further development of the discipline by arguing that the introduction of educational research in the thinking about teaching in the discipline is necessary for meaningful engagement with the current challenges. It is important to note that while the first goal of this article is concerned with showing how a specific educational approach influences teaching practice, this final goal is more general in that it is not an attempt to present a specific teaching method but rather a broader, interdisciplinary approach that could characterise thinking about teaching in the discipline. It has been argued that cognizance of and engagement with educational scholarship is part of a larger process of reviewing thinking about teaching and learning. This process is, according to Ho et al (2001:145), a prerequisite for any eventual deep rooted changes in teaching practices. For conceptual purposes then it is important, especially with reference to this final goal, to distinguish between teaching practice and theoretical approaches to teaching. Others have also concluded that thinking about teaching Classics (especially languages) should precede changes in practice (Morse 2004).

\section{Thinking about the Community of practice and identity trajectories}

In the previous section we gave a very brief definition of a community of practice. In this section we will attempt to identify the constituent parts of such a community in more detail. For the sake of context it is important to note that the term "Communities of practice" was used by Lave and Wenger (1991) in their study of apprenticeship ${ }^{2}$ as a model for learning. The concept conceives learning as a social matter and diverges

Lave \& Wenger 1991 conducted a number of case studies focusing on how children in certain cultural setting learn trades through observation and participation (by acting as apprentices) rather than through formal instruction. 
from the more traditional psychological models of learning (Lave 1993). Psychological / cognitive models of learning represent a traditional Cartesian view of knowledge and learning that assumes that "knowledge is a kind of substance and that pedagogy concerns the best way to transfer this substance from teachers to students" (Brown \& Adler 2008:18). This is in contrast with the view of situated (or sociocultural) learning that suggests that "the community ... acts as a living curriculum for the apprentice" (Wenger 1998). The distinction between the psychological / cognitive and the sociocultural approaches to learning is characterised by Paavola et al (2004:557), following Sfard (1998), using the metaphors of acquisition and participation. The acquisition approach holds that knowledge is a property of the individual's mind and that learning happens through transferral of knowledge. In contrast to this the participation mode / metaphor, to which Lave \& Wenger's (1991) notion of "legitimate peripheral participation" belongs, states that knowledge is not situated only in the mind of the individual but that it is also an aspect of participation in cultural practices (Paavola et al 2004) and that learning is a function of participation in the practices of the community which the learner has entered. Dall'Alba \& Barnacle (2007) present a similar argument in claiming that "learning is not confined to the heads of individuals, but involves integrating ways of knowing, acting and being within a broad range of practices" (2007:683). Communities of practice, in the sense advocated by Wenger (1998), thus refer to a specific mode of learning.

Barab, Barnett \& Squire (2002:495) describe a community of practice as a group of people who are "socially interdependent, and who share mutually-defined practices, beliefs, and understandings over an extended time frame in the pursuit of a shared enterprise". Traweek (1988) offers a slightly different perspective on the description of a community of practice by suggesting that it refers to "a group of people who have shared past, hope to have a shared future, have some means of acquiring new members, and have some means of recognizing and maintaining differences between themselves and other communities". An overview of literature on communities of practice offers numerous other descriptions but, for the purposes of this article, the above mentioned will suffice. From the given descriptions it is clear that a community of practice exhibits the following constitutive parts:

- It is a sustained collective (Barab, Makinster et al 2004:5), i.e. a collective with a significant history and historical heritage (Wenger 1998).

- The community is a collective with a shared domain of interest (Wenger 1998). Its identity is defined by this shared interest.

- The community has shared goals, practices, values and beliefs. Communities of practice work towards shared goals but also towards the goals of individual members. These individual goals are not divorced from the goals of the collective.

- The community has the ability to reproduce itself and guide new members from peripheral participation to core participation through enculturation (Lave 1993). The fact that new members are peripheral participants does not mean that they make no contribution to the development of the 
community. As peripheral participants new members, by virtue of the fact that they are already members of the community, are in a position to contribute to the community.

- A community of practice is built on interaction and participation of members. Members thus learn from each other even though they possibly often work alone (Wenger 1998).

Identity development is an all important aspect of the community of practice. Lave (1993:65) has suggested that "developing an identity as a member of a community and becoming knowledgeably skilful are part of the same process, with the former motivating, shaping, and giving meaning to the latter, which it subsumes". Wortham (2004:716) reiterates this in the expression that "learning changes not just what the learner knows ... but also who the learner is". While it should be clear that there is a definite connection between learning and identity, it is also necessary to describe the nature of this connection. It is tempting to present the relationship between identity and learning as a causal one, in other words suggesting that identity influences learning or vice versa. Thinking in these terms however limits our understanding of the role of identity in learning, both in philosophical and practical terms. Here the "Communities of practice" framework again offers us an alternative. Instead of conceptualising learning and identity as two separate variables (with one being a dependent and the other an independent variable) we can think of both learning and identity development as similar movements within a specific community of practice. In fact Wortham (2004:716) suggests that learning is equivalent to changing one's position in a community, a description that also applies to identity change in communities. In terms of the framework we adopt here we can say that learning and identity development are not necessarily causally linked but rather that they are dimensions of the same process. The process of developing an identity as a member of a community of practice is not external to the community itself. In fact Välimaa (1998:131) has pointed out that the process of identity development and change happens through dialogue with, what Taylor (1991) called, "significant others". The individual's identity as a member of the community is not something to be attained before significant participation and contribution becomes possible. Rather, the student enters the community as a legitimate peripheral participant with the potential to become a full participant as the required identity shifts become manifest (O'Donnel \& Tobbell 2007:315). Successful learning is thus inextricably connected (but in a noncausal way) to the identity trajectory of the learner. This brief description of the nature of the connection between identity and learning does not suggest that the relationship is a simple one. What it is meant to do is to encourage research, dialogue and reflection on the connection in order to improve our understanding and, ultimately, the way identity is dealt with in teaching.

\section{Contextualising the project}

The Department of Ancient Studies (Stellenbosch University) is the institution's intellectual home for the broader Classics discipline. Courses focusing on languages 
(Greek and Latin), Classical Legal Culture and Ancient Cultures ${ }^{3}$ all form part of the Department's Classical offering. The Department has a proud teaching and research profile that is evidenced by both its research outputs and the fact that numerous teaching accolades have been bestowed on lecturing staff. ${ }^{4}$ But the challenge of a changing student body (in terms of numbers, diversity and expectations), the growth and development of the discipline and the higher expectations that the University has of lecturers in terms of both research and teaching outputs are concerns for the Department.

It is within this institutional context that a project was devised to address some of the challenges that continue to face the Department in terms of its teaching role. The project is located within a broader NRF sponsored project hosted by the University's Centre for Teaching and Learning, the aptly named "Critical Professionalism" project. This endeavour has three broad objectives through which it attempts to develop a "reconstructed professionalism" (Walker 2001). Reconstituting academic professionalism, it has been argued, is necessary if academics are to survive and respond to the new contextually driven challenges they face. The objectives of the NRF project are 1) to generate a model of the professional development of lecturers seeking to enhance their own reflective and inclusive practices, 2) to contribute to the debate in South African higher education about the norms informing curriculum renewal and 3) to enhance our understanding of the way students' learning biographies and prior experience impact on their present learning in contexts of diversity. Within the broader "Critical Professionalism" project a series of subprojects have been developed in order to further understanding of the requirements of the mentioned reconstructed professionalism.

The sub-project relevant to this article is a collaborative effort between a lecturer in the Department and an educational adviser of the Centre for Teaching and Learning. The project has two broad but interrelated goals. Firstly it seeks to improve student performance in all undergraduate Greek courses. Even though the project focuses on first-year students it is hypothesised that engaging students at this level in the community of practice will result in improved performance beyond the first-year. Secondly it attempts to increase students' involvement in the discipline beyond the compulsory requirements of their programmes ${ }^{5}$. This goal is about more than just increasing postgraduate numbers. In terms of the "Communities of practice" framework explained earlier it is about sustaining and developing the community by continuously reproducing the community through the introduction of new members. In order to achieve these goals the project focuses on the development of student identity in the discipline.

3 This course consists of themes and content derived from both the discipline of Classics and the sister discipline of Semitic / Ancient Near Eastern Studies.

4 These include Rector's Awards for Excellence in Teaching and numerous nominations to attend the Rector's dinner for top-performing First-year students (an event that is only open to lecturers invited by the University's top-performing First-year students).

5 Most of the undergraduate Greek students are enrolled for programmes in Theology. These programmes generally only require that students complete Greek II. 


\section{Conceptualising the project}

The project attempts to introduce students to communities of practice in the discipline by offering, as part of the curriculum, innovative activities and spaces where students and practitioners interact with each other addressing issues within the discipline and where students have both the freedom and guidance necessary to develop and change their identity relationship to the discipline. It should be made clear from the outset that the discipline is not encapsulated within a single community of practice (hence our preference for the plural "communities of practice"). In fact one of the greatest challenges related to the application of this framework is distinguishing between various communities in a single discipline. To add to the complexity there is always the possibility that identity characteristics are shared among different communities of practice. This is to be expected when dealing with such a complex concept as identity. Having said this, as long as there is an awareness of these conceptual challenges the complexity should not discourage us from employing the framework. The complexity can only contribute to our understanding of the connection between identity and learning.

In order to bring some coherence to the possible conceptual confusion, Wenger (1998) identifies 3 different modes of belonging to a community of practice namely alignment, imagination and engagement. These modes represent different organising principles for participants to categorise their identity characteristics and are determined, at least to an extent, by the literary practices students are expected to adopt if they are to succeed (McKenna 2004). The first refers to the extent that the individual subscribes to the "common agreed systems of rules, values or standards, through which we can communicate within a practice and through which we can belong to it" (Solomon 2007:83). In a negative sense alignment means that students adopt mechanical approaches to participate in the community of practice but do not share the "ownership of meaning" (Wenger 1998:206). In this mode of belonging students tend to be concerned with results ("What is the answer?") rather than processes ("Why is this the answer?"). It is in this mode that students often experience their identities as marginalised as they seem to make no contribution to the community and simply follow the rules. In the case of the students in this project negative alignment results in mechanical interaction with Greek without any real engagement. This results in the well known concern that students can recite grammatical rules and paradigms but lack the ability to use these as instruments in translating and interpreting texts. As assessment often rewards rote learning it might not be necessary for students to "belong" in any other way. This is a crucial consideration in any attempt to understand students' identity development (Solomon 2007:81). The next mode of belonging, imagination, refers to students' concern with locating themselves within the social world of the community of practice. Belonging in this sense means that students are aware that their actions are part of a larger coherent whole and that they view themselves and the world in terms of their perceived belonging to the community of practice. This kind of belonging results in students conceiving themselves as aspirant "classicists" or at the very least "active participants in the Greek community of practice". Finally, if students belong through 
engagement they are actively involved in adopting the meaning of the community as well as constructing meaning in the community. Their identity is then described by Wenger (1998:202) as an "identity of participation". Their identity allows them to critically reflect on their own involvement in the discipline as a means to further stabilise their identity.

Solomon (2007) stresses that it is possible for students to appear marginalised and excluded in terms of one of these modes (most often alignment) while at the same time having a stronger attachment to a community through another mode. Where this is the case it is often because of a mismatch between the wider disciplinary community's values and those of the undergraduate and classroom communities of practice (2007:88). It is thus possible, for example, that students perceive themselves to belong to the wider community in the mode of imagination by reflecting on their experiences in the discipline and by considering the implications of the discipline for their careers while at the same time being excluded in the classroom community because of the dominant values (especially reflected in assessment practices) that often encourage more alignment and less imagination and engagement.

\section{Inducting students in a community of practice}

In this project students engage in a variety of the practices of the communities within this discipline in order to move from peripheral participation to full or at least increased participation. The focus is thus not only on what students need to know but also on what they are supposed to become if they are to be successful. Current as well as retired lecturers and practitioners in the field are drawn into the project as core members of some of these communities of practice (in particular the research community) while senior undergraduate students are also included as members who find themselves in terms of skills and identity at an intermediate level. In terms of the framework students are viewed as legitimate, albeit peripheral, participants in the communities of practice in the discipline. Academic success, in terms of this framework, is conceptualised as students' development from peripheral members to members engaged in full participation. This implies a change of identity for the students or, put differently, it means that there is identification ${ }^{6}$ with and valuation of the characteristics that are defining of the discipline and participants in the communities of practice. Bilgrami (2001:7149) has argued that in order for someone to identify with an "identity-imparting characteristic" they must minimally value that characteristic. Thus, in order for a student to have adopted the identity of a disciplinary community of practice, the student must value the fact that he/she belongs to a group that engages with the discipline. Furthermore this value needs to be more unrevisable than other values the individual holds (Bilgrami 2001:7150) meaning that the individual would not be likely to give up this value when changes in the structure of his / her identity are required.

In order to influence the development trajectory of students' identity (or, put differently, to influence their valuation of the characteristics of the identity and to entrench the value so as to render it more unrevisable than others), a series of

6 See Hardin 2001 for some distinction between "identity" and "identification". 
activities were designed for incorporation in the regular curriculum. These include journaling, interacting with existing members of the disciplinary community and introducing peer assisted learning opportunities (see descriptions of each of these below). While similar interventions have previously been part of the curriculum they have often been arbitrary. This particular project attempts to locate these interventions in a specific theoretical framework thus allowing an approach to the development of student identities that is coherent and, to a greater extent, predictable.

\section{Journaling}

In the context of Higher Education, journaling refers to the activity of noting thoughts one has about a specific discipline as these arise in the engagement with the discipline. The value of journaling as a learning instrument is based on the Vygotskyan suggestion that language and thought are dialectically related and that both can be changed through representation (Vygostsky 1962). Writing thus engages the student, both in thought and expression, in meaning making (Borasi \& Rose 1989:348). In fact, writing seems to be one of the central structures of the "becoming" process in communities of practice (Barab, Barnett \& Squire 2002:493). The benefits of journaling includes the fact that the activity has therapeutic value, it increases the learning of content, it improves learning and problem solving skills and it allows for changed conceptualisations of the students' perceptions of the discipline (Borasi \& Rose 1989:353-358). Journaling further offers benefit to the lecturer as it allows insight into student experiences and continuous feedback on the course. This in turn supports lecturers' reflective practices.

Students should be allowed relative freedom to determine the content and extent of their journal entries but they should be encouraged to keep track of more than just events or personal thoughts (Borasi \& Rose 1989:348). For the journaling to be of value in the process of learning and identity development, students should interact with class material or lectures, focusing on the implications for their own intellectual advancement and practice. In this project freedom to write is combined with guided reflection. While students are encouraged to record their own reflections they are also given guidance to reflect on the nature of the community which they have entered peripherally, the values guiding and sustaining this community and their own identification with and participation in the community. As most of the students in this project are enrolled for programmes in Theology the description of an identity trajectory is even more complicated. The project hypothesises that journaling will assist students in transferring thinking about the Classics discipline to their conceptions of their primary academic concern, namely their theological studies. Through their journal entries it could be possible to identify integration (or lack thereof) of their participation in the Classics disciplinary community with their participation in other disciplinary communities. Once such integration is realised students are less likely to revise their identity as members of the Classics disciplinary community when changes in their identity structure (which conceives of students as theologians) occurs. Journaling is thus a form of reflection allowing students to "think on paper" (Borasi \& Rose 1989:364). Through such reflective action students are 
constructing their own identity (Giddens 1991) while at the same time interrogating the "epistemological unconscious" and "social organisation" of the discipline (Bourdieu \& Wacquant 1992:40).

\section{Interacting with core participants}

While students are exposed to a core participant in the form of their lecturer, their interaction with this core member happens largely in isolation to the other activities of the broader disciplinary community of practice (while being situated within a different community - the classroom community - that relates to the discipline). In order to expose students to the ways of thinking and doing that prevail in the broader community, a series of events involving a broader representation from the community has been designed for the project. These events include one which simulates debate involving students and lecturers regarding the necessity of an education including the Classics. The aim of this debate is not primarily concerned with explicit content but rather with the values and practices exhibited by the core participants. This activity was included in the pilot phase and seemed, anecdotally, to be successful. However, because no space was created for students to reflect on and record their experience of this event, it was impossible to make any assertions regarding the influence the event had on the students' identity development. This oversight will be corrected once the project is fully implemented as students will be required to reflect on these experiences in their journals. In terms of the project's theoretical framework this event reflects part of the process of facilitating "the participation of the less proficient participant by modifying his or her interaction" (Peyton 1993:4). This is clearly what Lave and Wenger (2002:57) had in mind when they stated that "In the Community of Practice the newcomer is not only a learner, learning in situ, but also an active participant in the social community. As a member of a social structure the newcomer is accepted and "legitimate", even though being located in the peripheral zone. Through this legitimate peripheral participation, the newcomer develops identity through meaningful activity in the community and gradually moves towards full participation."

The second event in this series requires the participation of at least two well established members of the disciplinary community. These members are invited to a session where they both present a short paper on a specific Greek text but from different perspectives and arriving at different conclusions. Although the entire exercise might seem contrived it again exposes the students to important values underlying the disciplinary community. This is again in keeping with the goals of a community in an education context. Bielaczyc \& Collins (1999:270) has pointed out that students learn to synthesise multiple perspectives in communities, a skill necessary for interacting in and with an academic community. Hodge, Haynes, LePore, Pasquesi \& Hirsh (2008) frame it differently. They state that a goal of Higher Education is to cultivate the "student as scholar" with "scholar" being defined as an "attitude, an intellectual posture, and a frame of mind derived from the best traditions". By creating an opportunity to synthesise perspectives, students are offered a chance to gain the value system and foundational competencies (Hodge et al 2008) 
of their discipline (Classics in this case). At the end of this event students are also required to reflect on their experience of the differing opinions in their journals. What is important in this event is to "connect" students to the conversation by selecting a text that is relevant to issues that are important to students. Morse (2004) has argued that by focusing on what is relevant to students, "networks for retention and understanding" (2004:48) are created.

A third activity introduces students to some of the instruments employed by members of the disciplinary community. A knowledgeable practitioner guides students through the use of some of the online tools available to those who share an interest in the Classics. The event is concluded with students accessing some of these in order to complete a short assignment. A final event offers students the chance to present short papers to an audience of established members of the broader community and to interact with these members. In order for these activities to be of value in terms of the process of the development of identity, they should not be evaluated for their creativity or the extent to which they are innovative. Their value should rather be judged in terms of the theoretical framework outlined earlier.

Through these events students engage with the broader disciplinary community of practices and its attendant norms and values rather than with the classroom community where different norms and values often require different identity moves from students. Realistically speaking students aren't likely to entrench identities that bind them to the Classics through these activities. However, the activities do create an opportunity for students to be exposed to the community as "legitimate" participants as it allows them to be part of the community's activities. If their interaction with the discipline is restricted to their regular classroom activities, students are less likely to view themselves as "legitimate" members of the disciplinary group and are more likely to conduct their academic training in a strategic manner.

\section{Peer assisted learning}

By introducing peer assisted learning the project exposes students to academic activities conducted by fellow community members who are closer to the peripheral participants than to the core participants in terms of identity development and skills. If interaction is limited to core participants, the identities that need to develop might seem alien and unreachable. By interacting with others members of the community of practice identity development is scaffolded. The introduction of peer assisted learning is facilitated in a number of ways in this project. Firstly students are drawn into smaller group tutorials where they are encouraged to complete class assignments under the guidance of a senior undergraduate student. Ideally tutorials should not be events where the transference of content is the primary goal. Transference could be an instrument but the goal should be transformation of identity through social learning. Furthermore students are also encouraged to adopt learning partners. Learning partners need to have similar abilities and, preferably, similar learning styles (Morse 2004:49). 


\section{Concluding thoughts}

In tracing the origins of the notion of "liberal" education, Nussbaum (1997) calls on the Stoic idea that education "liberates the mind from the bondage of habit and custom" (1997:8). In a sense this might be an appropriate metaphor for the aim of this article. It has been an attempt to move thinking about teaching in the Classics beyond habit and custom. Those looking for specific methods that can be applied in their own contexts might be disappointed as the project outlined here is a limited and possibly context-constrained. Those embracing the idea that teaching can also be a scholarly activity, however, might be stimulated to respond.

Having described a project with rather ambitious goals it is perhaps important to conclude by referring to some of the challenges this project expects to face. Probably the greatest challenge facing this project is that of transforming existing perceptions. Firstly the project attempts to establish a view of the discipline based on an identity of inclusion in the disciplinary community rather than an identity of exclusion based on individual performance. In order to achieve this, a perceptual change is required, namely that of the existing members of the established disciplinary community. These members are, after all, the participants who will legitimise the identity of the new peripheral participants. An exclusionary paradigm that conceives of students as outsiders that only gain access to the community through certain rites of passage (e.g. successful completion of undergraduate studies, enrolment in post graduate studies, top grades) is what Sinfield, Burns \& Holley (2004:147) refer to when they argue that "The unequal power relations of educational discourse can very easily reinforce the negative self-perceptions of students, as can lecturers, perhaps, who see themselves primarily as ... (keepers of the academy), rather than as educators". And to further complicate this task for students we remind the reader that mismatches between the values of classroom communities and the broader communities often occur, leaving students uncertain of the identity moves required to succeed. It is hoped that this suggestion of a paradigmatic shift is contentious enough to elicit reflection and response from readers.

There are also conceptual challenges. Communities of practice are generally defined as "a group of people who are socially interdependent, and who share mutually-defined practices, beliefs, and understandings over an extended time frame in the pursuit of shared enterprise" (Barab, Barnett \& Squire 2002:495). Given this description of a community of practice the project is faced with the challenge of defining the community to which it seeks to induct learners. This challenge also extends to students' understanding of the nature and membership of the disciplinary community. Because most of the students in this project are Theology students and are likely to pursue careers in Theology or church ministry, questions regarding the relation between the Classics and Theology as disciplines need to be considered. How are students to develop identities that bind them to the discipline of Classics if their professional identity is to be found in another discipline (Theology)? The answer, we suspect, is to be found in the way that the Classics disciplinary community conceptualises its relation to other disciplines. It is hoped that this article will promote reflection among established members of this community which in turn will 
contribute to a clearer understanding and description of the identity that binds this particular community.

Related to this challenge is the vexing conceptual problem of delineating communities of practice in general, both theoretically and in practice. The relatively simplistic manner in which we have dealt with communities of practice should not suggest to the reader that the framework is a simple one. If Dall'Alba \& Barnacle's (2007) argument that higher education in general requires a move away from epistemology to ontology is taken seriously, the reflection suggested above on the 'being' of the Classics discipline as a community of practice is of vital importance. Without a clear (and articulated) notion of what students are expected to become (as opposed to what they are supposed to know), the Classics discipline is likely to retain the challenge of students viewing the discipline in a purely instrumental way.

A final summary perspective on this project is provided by O'Donnel \& Tobbell. They argue that "Success in an education system can be thought of as full participation - that is, individuals adopt and perform the valued practices of that community and in so doing contribute their own experience and modify practice and shift values" (O'Donnel \& Tobbell 2007:315). This suggestion succinctly summarises the theoretical assumptions of the entire project as well as the belief that this project has value not only for the learners but also for established members of the disciplinary community. It is also important to note that this induction of students into a disciplinary community of practice is not an event but rather a process of negotiating meaning (Wenger 1998) and reconstructing identity (Barab, Barnett \& Squire 2002). There is a realisation in the project that the stated goals are ambitious and, possibly, even unrealistic. However, external and internal pressures have left the project with an opportunity to embark on this ambitious undertaking.

\section{BIBLIOGRAPHY}

Barab, S A, Barnett, M \& Squire, K 2002. Developing an empirical account of a Community of Practice: Characterizing the essential tensions. The Journal of the Learning Sciences 11.4, 489-542.

Barab, S A, MaKinster, J \& Scheckler, R 2004. Characterizing system dualities: Building online community. In Barab, S A, Kling, R \& Gray, J (eds). Designing for virtual communities in the service of learning. Cambridge, MA: Cambridge University Press.

Bilgrami, A 2001. Identity and Identification: Philosophical aspects. In Smelser, N J \& Baltes, P B (eds). International Encyclopedia of the Social \& Behavioral Sciences. Oxford: Elsevier.

Borasi R \& Rose, B J 1989. Journal writing and mathematics instruction. Educational Studies in Mathematics, 20.4, 347-365.

Bourdieu, P \& Waquant, L 1992. An invitation to reflexive sociology. Chicago: University of Chicago Press.

Brown, J S \& Adler R P 2008. Minds on fire: Open education, the long tail, and learning 2.0. Educause Review, 43.1, 16-32. 
Bielaczyc, K \& Collins, A 1999. Learning communities in classrooms: a reconceptualization of educational practice. In Reigeluth, $\mathrm{C}$ (Ed). Instructional-design theories and models: A new paradigm of instructional theory vol. 2, Mahwah, N J: Lawrence Erlbaum Associates.

Culham, P \& Edmunds, L 1989. Classics: A Discipline and profession in crisis? Lanham, MD: University Press of America.

Dall'Alba, G \& Barnacle R 2007. An ontological turn for higher education. Studies in Higher Education, 32/6, 679-691.

Demos, M 1995. Classics outside the Classics Department. Transactions of the American Philological Association, 125, 321-324.

Du Toit, J S 2008. South African Higher Education and Near Eastern Studies (1): Some issues in the assessment of student learning. Journal for Semitics, $17.2,423-442$.

Galinsky, K 1991. Classics beyond crisis. The Classical World, 84.6, 441-453.

Giddens, A. 1991. Modernity and self-identity: self and society in the late modern age. Cambridge: Polity Press.

Hardin, R 2001. Identity: Social. In Smelser, N J \& Baltes, P B (eds). International Encyclopedia of the Social \& Behavioral Sciences. Oxford: Elsevier.

Ho, A, Watkins, D, Kelly, M 2001. The Conceptual change approach to improving teaching and learning: An evaluation of a Hong Kong staff development programme. Higher Education, 42.2, 143-169.

Jacobs, C 2007. Mainstreaming academic literacy teaching: Implications for how academic development understands its work in higher education. South African Journal of Higher Education, 21.7, 870-881.

Kitchell, K F, Phinney, E, Shelmerdine, S, Skinner, M 1996. Greek 2000. Crisis, Challenge, Deadline. The Classical Journal. 91.4, 393-420.

Lave, J 1993. Introduction. In Lave, J \& Chaiklin, S (eds.). Understanding practice: Perspectives on activity and context. New York: Cambridge University Press, 3-34.

Lave, J 1996. Teaching as learning, in practice. Mind, Culture, and Activity, 3.3, 149-164.

Lave, J, \& Wenger, E 1991. Situated learning: Legitimate peripheral participation. Cambridge, UK: Cambridge University Press.

Lave, J \& Wenger, E 2002. Legitimate peripheral participation in communities of practice. In Lea, M R \& Nicoll, K (eds). Distributed learning. Social and cultural approaches to practice. London: Routledge.

McKenna, S 2004. The intersection between academic literacies and student identities. South African Journal of Higher Education, 18.3, 269-280.

Morse, M 2004. Enhancing the learning and retention of biblical languages for adult learners. Teaching Theology and Religion. 7.1, 45-50.

Nixon, J, Marks, A, Rowland, S, Walker M 2001. Towards a new academic professionalism: A manifesto of hope. British Journal of Sociology of Education, 22.2, 227-244.

Nussbaum, M C 1997. Cultivating Humanity: A Classical defense of reform in liberal education. Cambridge, Massachusetts: Harvard University Press. 
O'Donnell, V L \& Tobbell, J 2007. The transition of adult students to higher education: Legitimate peripheral participation in a Community of Practice? Adult Education Quarterly, 57.4, 312-328.

Paavola, S, Lionen, L \& Hakkarainen, K 2004. Models of innovative knowledge communities and three metaphors of learning. Review of Educational Research, 74.4, 557-576.

Peyton, J K \& Staton, J 1993. Dialogue journals in the multilingual classroom: Building language fluency and writing skills through interaction. Norwood, New Jersey: Alex Publishing Corporation.

Pottle, V F 1937. Teaching New Testament Greek. Journal of Bible and Religion, 5.4, 168-170.

Sfard, A 1998. On two metaphors for learning and the dangers of choosing just one. Educational Researcher, 27.2, 4-13.

Sfard, A \& Prusak, A 2005. Telling identities: In search of an analytic tool for investigating learning as a culturally shaped activity. Educational Researcher 34.4, 14-22.

Sinfield, S, Burns, T \& Holley, D 2004. Outsiders looking in or insiders looking out? Widening Participation in a post-1992 University. In Satterthwaite et al (eds). The Disciplining of Education: new languages of power and resistance. Stoke on Trent: Trentham Books.

Solomon, Y 2007. Not Belonging? What Makes a Functional Learner Identity in Undergraduate Mathematics? Studies in Higher Education, 32.1, 79-96.

Taylor, C 1991. The ethics of authenticity. Cambridge, Massachusetts: Harvard University Press.

Traweek, S 1988. Beamtimes and lifetimes: The world of high energy physicists. Cambridge, Massachusetts: Harvard University Press.

Välimaa, J 1998. Culture and identity in higher education research. Higher Education, 36.2, 119-138.

Vygotsky, L S 1962, Thought and language, MIT Press, Cambridge, MA.

Wenger, E 1998. Communities of practice. Cambridge, England: Cambridge University Press.

Wortham, S 2004. The interdependence of social identification and learning. American Educational Research Journal, 41.3, 715-750. 